\title{
Performatividade Pajubá
}

Performativity of Pajubá

\author{
João Manuel de Oliveira' ${ }^{1}$ (i) 0000-0002-2793-2946
}

'Universidade Federal de Santa Catarina, Programa de Pós-Graduação em Psicologia, Florianópolis, Santa Catarina, Brasil.88040-900-ppgp@contato.ufsc.br

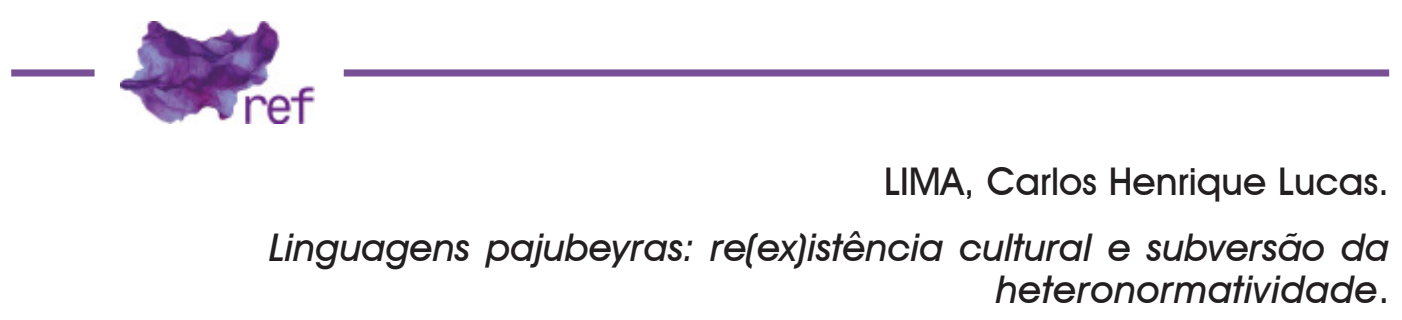

Salvador: Devires, 2017.

Este livro, editado pela Devires, que no panorama editorial brasileiro tem sido vital para sustentar e fomentar uma cultura de literatura e ensaio queer, é um marco no pensamento sobre subversão da heteronormatividade que poderíamos chamar de kuir/queer. Carlos Henrique Lucas Lima, autor da obra, recorre ao termo queer, sem o manter acriticamente. Toda a obra é precisamente uma celebração, de formas de resistir culturalmente, de torcer a norma e ressignificá-la, de produzir uma teoria e prática torcidas.

Carlos Henrique Lucas Lima é professor na Universidade Federal do Oeste da Bahia e escreveu este livro como resultado do seu doutoramento em Cultura e Sociedade na Universidade Federal da Bahia e fez esse trabalho no CuS, Cultura e Sexualidades, recentemente constituído como núcleo de pesquisa. Com formação inicial em Letras e História da Literatura, o seu olhar simultaneamente interdisciplinar e indisciplinar ajuda a entender algumas das propostas intrincadas deste texto híbrido que a editora Devires publicou.

O autor mistura um conjunto de gêneros, crônica, ensaio, poema, para ensaiar uma escrita pajubeyra. O pajubá, língua ou gíria falada por dissidentes sexuais e de gênero no Brasil, que mistura léxico yorubá, nagô e outros, não é estudado aqui numa acepção sociolinguística. Antes, o pajubá é entendido e usado como modo de subjetivação. Assim, não há um sujeito que fala o pajubá e se antecipa a ele, é o pajubá que cria um sujeito pajubeyro performativamente. Dessa maneira, o autor vai proceder a uma arqueologia dos modos como o pajubá não só constitui outros sujeitos, mas a si mesmo como parte de uma escrita pajubesca. Carlos Henrique Lucas, conhecedor profundo de teoria feminista e teoria queer, propõe mesmo um exercício de antropofagia acompanhando esse pajubá, usando estas teorias como pretexto para alimentar o pajubá que as mistura e as dá de novo, num rizoma de permutações e combinações. No poema "Serventia Pajubeyra"

\author{
Para apagar as palavras \\ Desbotar os sentidos \\ Rasurar a semântica \\ E sambar nenada na cara da sociedade \\ Para isso é que serve o pajubá (Carlos Henrique LIMA, 2017, p. 156).
}

o autor dá-nos a sua proposta de trabalho. Adianto mais algumas possibilidades de leitura.

Na sua proposta de rasurar a semântica, o pajubá permite a constituição de solidariedades e alianças, sem apagar as especificidades. Trata-se de um pajubá que tanto constitui beeshas 
fechativas como travestis. Então essa pode ser a marca de uma aliança, que, trabalhando com essas diferenças, possa fazer surgir focos de resistência à cisheteronormatividade na sua política de apagamento e destruição material e epistemicida. Este livro se constrói simultaneamente como uma forma de impedir o epistemicídio, de destruição das pessoas e dos saberes kuir e trans* , mas igualmente produz pajubá. Não descreve apenas, produz parcialmente o que descreve. Essa ressignificação segue de perto uma lógica de proliferação e multiplicidade, alentando mais beeshas e travestis a produzir(em-se) pajubá como forma de resistir. O domínio da linguagem e da nomeação é o das relações de (saber) poder. O pajubá cria formas de nomeação que vão não só produzir subjetividades de resistência à heteronorma, mas simultaneamente criar formas de nomear outras, que quebram a eficácia da norma. Apresentado o argumento central do livro, a sua concepção vai obedecer a uma lógica de escrita de hibridização e de antropofagia. Poderíamos afirmar que o livro é uma obra em pajubá, no sentido da recusa de uma normalização, de uma forma única de escrita. Antes a obra recorre muitas vezes a termos do pajubá para pensar com eles. Não irei usar esses exemplos porque considero mais relevante lê-los no contexto da obra, não como curiosidades. É precisamente essa a opção epistemológica e metodológica de Carlos Henrique Lucas Lima: não tratar o pajubá como objeto a ser estudado, antes entendê-lo como parte central de um processo de constituição de sujeito.

Longe das perspectivas de um LGBT universal e identitário, neste processo travestis e bichas constituem-se através desta linguagem. Igualmente mostrando o seu carácter indisciplinar, a obra de Carlos Lucas Lima está muito mais interessada em provocar tensões e debates do que em contribuir para uma determinada disciplina. Este trabalho tensiona a própria ideia de etnografia e de disciplina, porque se configura como produtor e produto do pajubá. O texto pretende antes desestabilizar os equilíbrios de forças disciplinares para pensar contra elas e com elas, no mesmo sentido que Gayatri Spivak (1999) recorre quando fala em ler com e contra (reading against the grain) no espírito da desconstrução de Derrida. Então, a proposta desta obra é extremamente inovadora, como bem aponta Leandro Colling no prefácio, por precisamente não se ater aos modos convencionais de produção textual como forma final, o que reforça o carácter indisciplinar da obra em questão. E não faz a separação clássica sujeito objeto, antes opta por uma ótica de performatividade pajubá, em que o próprio que escreve se produz e é produzido pelo chamado objeto de estudo.

Assim estamos perante uma visão pós-estruturalista em que a ação produz o agente. Manifestamente nesta obra, não se encontrará um olhar sobre pajubá, antes se produz um pajubá e, simultaneamente nessa ação, se produz quem escreve. Então este ensaio não descreve, ele é muito mais performativo. Através de criação de figurações como a Gya Pajubeyra, auto(des)identificação, por aludir a uma forma de identificação que quebra o código do binarismo e da heteronormatividade da produção acadêmica e científica, temos um modo de contar profundamente alterado. Umas escritas antropofágycas (sic) que pretendem nomeação, devoração e devolução da heteronorma, um registo e modo pajubérico de experiência queer que ridiculariza as normalidades. Este modo de escrever produz um modo de subjetivar que é profundamente marcado pelas potencialidades queer subalternas, que permite ao autor uma viagem simultânea pela teoria pós e decolonial, produzindo um queer que não é apenas o eco do euro e anglocentrismo, mas marcado por uma performance escritural brasileira, latino-americana que entoa e redige o texto a partir de uma múltipla ressignificação das resistências. Então, esta obra se inscreve como ensaioliteratura pajubeyra que resiste. A pajubeyra é bilingue e tanto fala hétero como pajubá. Afinal, estas culturas falam outras línguas e a tradução é também um ato de traição, como bem sabemos.

Este livro trabalha a partir de algumas potências que o pajubá nos dá a conhecer e que podemos entender como fissuras:

- fissura na língua-nação, a crença da nação como homogeneidade linguística que a existência do pajubá e de outras línguas coloca em causa como pura diferença e proliferação continuada dessas diferenças. Então, trata o pajubá como um discurso crítico e sinalizador dessa multiplicidade de formas de dizer e de ser.

- fissura no dimorfismo colonizador de género, o género enquanto diferença sexual binária e marca do pensamento colonial é afrontado pela multiplicidade de gêneros e sua fluidez. Recorrendo ao pajubá como contramodelo de subjetivação, permite a proliferação de discursos paródicos e críticos do binarismo.

- fissura nos modelos convencionais de sociabilidades, o pajubá inaugura outras maneiras de relacionalidade para além do centramento no modelo burguês e eurocêntrico de família, precisamente por se constituir como uma possibilidade de estilo de vida. Assim, o pajubá consiste igualmente num modo de possibilitar determinadas alianças e solidariedades, pensado então como uma forma de construir possibilidades políticas.

A vontade de imaginar o pajubá já não apenas como um conjunto de palavras, indecifráveis para quem está fora do meio, é um exercício de dessubjugação dos conhecimentos. Implica o recurso à imaginação teórica e política para pensar as multiplicidades e as articulações que é raro, inclusive nesta área do saber. Então trata-se de um trabalho não só profundamente original 
como marcado pela inovação teórica e crítica, escrito a partir do enredo do que significa "sambar na cara da sociedade" (LIMA, 2017, p. 156), como nos alerta a Gya Pajubeyra que baixa em Carlos para nos tirar da reflexão acadêmica e do ativismo político e permitir linhas de fuga. O texto está cheio destas linhas de fuga, redigido ele mesmo a partir da fissura com as crônicas, publicadas em blog, que nos remetem para a situação de um ensaio de como escrever o texto, passando o próprio ensaio e as suas mil rasuras a constituir o espaço do texto. Agrada também a forma não definitiva e não fechada como a Gya escreve a par do rigor conceptual quando Carlos escreve. Há momentos que se confundem, se afinal ele e ela partilham os mesmos dedos que escrevem, em outros momentos a obra é escrita a partir de várias vozes, que se juntam às de Gya e de Carlos.

É nestes momentos que o livro se mostra mais marcado por uma fluidez de estilos, uma invasão do binarismo pelas múltiplas formas e acaba por permitir a geração de um outro leque de possibilidades. A Gya não fala a uma só voz. Ela, antes, encarna várias possibilidades e identificações, hiperidentidades pajubeyras, identidades que são um devir constante. Assim o pajubá se constitui também como paródico em relação às normas, "tornando as normas absurdas e ridículas" (LIMA, 2017, p. 210). Este exercitar dos poderes paródicos da performatividade pajubá não deixa de considerar as posições sociais que se naturalizam e constroem determinadas formas de ser sujeito, apesar de sabermos que se tratam de identidades fluidas e circunstanciais: "Elas mais não são, concluo, que ficções bem fundadas na cara da verdade. Aquele make bem feito que abrilhanta a noite da mona" (LIMA, 2017, p. 215). Esta aparente tensão entre posições e identificações é mais uma forma de construir essa metafísica de substância que as normas de género parecem revestir-se, mas que na realidade, se tratam da enésima citação da cópia que não tem original, que é o género, como mostra Judith Butler (2017), em Problemas de Gênero.

O texto deste livro lança um olhar sobre homonormatividade evidenciando o modo como as pajubeyras, através das suas práticas e performances, incomodam e constrangem as gays durinhas, como designa Lima (2017) gays homonormativos. É como se o pajubá, como performatividade, implicasse já a priori uma lógica de performance de gênero marcada pela fechação, uma linguagem marcada pelo exagero e afetação. Necessariamente e para assegurar não só uma certa passabilidade e garantir assimilação, as gays durinhas estão forçadas a se adequarem e se conformarem às normas de gênero e, inclusive, fazerem o seu papel na economia política da heteronormatividade: serem discretas e fora do meio para com o seu silêncio cúmplice provarem que é possível ser assimilado. Ao passo que as fechativas recorrem ao pajubá, projeto que estranha a normalização e a parodia. Assim o pajubá implica não apenas aprender umas palavras de um léxico comum, mas antes propõe todo um outro código de legibilidade e controlo dos corpos. Trata-se de resistência, de uma lógica de subverter os códigos da heteronormatividade e sabotá-los (BUTLER, 2017).

Este livro não só é importante para documentar o que é o pajubá, mas ajuda sobretudo a entendê-lo como um fazer, uma prática. E não se trata de definir o que querem dizer as palavras dessa língua de resistência, é antes o que essa língua, essa performatividade faz. Então muito mais do que fazer funcionar uma gasta metodologia, este livro produz as várias faces do que está a estudar e, inclusive, produz um autor e subjetividades. Este livro traz-nos para uma outra ótica de pensar um queer que não precisa de ser absolutamente exterior, de outras latitudes ou legitimados pelas mesmas universidades do sudeste do Brasil, mas antes recorre à produção de um kuir ou cuir marcado geopoliticamente para pensá-lo nos trânsitos Rio Grande do Sul - Bahia, onde Carlos e sua Gya Pajubeyra transitam, se detendo nas saunas, lugares de pegação, pontos, falando com beeshas gongadas para sambar na cara da Norma. Trata-se de produzir também uma língua queer, ou melhor, uma língua pajubá que dê conta de fluxos e contrafluxos, da norma e da paródia da norma e crie sujeitos e predicados outros numa outra gramática política. É nesse aspeto, um livro surpreendente pela sua inovação, pelo seu semblante de resistência aberta e fundamental nos tempos tão perigosos que correm.

\section{Referências}

BUTLER, Judith. Problemas de Gênero: feminismo e subversão da identidade. Lisboa: Orfeu Negro, 2017.

LIMA, Carlos Henrique Lucas. Linguagens pajubeyras: re(ex)istência cultural e subversão da heteronormatividade. Salvador: Devires, 2017.

SPIVAK, Gayatri Chakravorty. A Critique of Post-Colonial Reason: Toward a history of the vanishing present. Cambridge, MA: Harvard University Press, 1999.

João Manuel de Oliveira (joao.m.oliveira@gmail.com) é professor Visitante Associado no Programa de Pós-Graduação em Psicologia da Universidade Federal de Santa Catarina e professor convidado no ISCTE-Instituto Universitário de Lisboa. Doutor e Pós-Doutor em Psicologia 
Social. Pesquisador em Estudos de Género, Teoria Feminista e Estudos Queer. Interesses de investigação: teorias de género, teorias queer e teorias trans, performatividade de género e pensamento pós-colonial e decolonial.

\section{COMO CITAR ESSE ARTIGO DE ACORDO COM AS NORMAS DA REVISTA}

OLIVEIRA, João Manuel Calhau de. "Performatividade Pajubá". Revista Estudos Feministas, Florianópolis, v. 27, n. 2, e59952, 2019.

\section{CONTRIBUIÇÃO DE AUTORIA}

Não se aplica.

\section{FINANCIAMENTO}

Não se aplica.

\section{CONSENTIMENTO DE USO DE IMAGEM}

Não se aplica.

APROVAÇÃO DE COMITÊ DE ÉTICA EM PESQUISA

Não se aplica.

\section{CONFLITO DE INTERESSES}

Não se aplica.

\section{LICENÇA DE USO}

Este artigo está licenciado sob a Licença Creative Commons CC-BY Internacional. Com essa licença você pode compartilhar, adaptar, criar para qualquer fim, desde que atribua a autoria da obra.

\section{HISTÓRICO}

Recebido em: 27/10/2018

Aprovado em: 12/02/2019

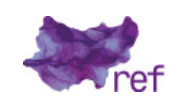

